Article

\title{
Property Criteria for Automotive Al-Mg-Si Sheet Alloys
}

\author{
Ramona Prillhofer ${ }^{1, *}$, Gunther Rank ${ }^{1}$, Josef Berneder ${ }^{1}$, Helmut Antrekowitsch ${ }^{2}$, \\ Peter J. Uggowitzer ${ }^{3}$ and Stefan Pogatscher ${ }^{3, *}$
}

1 AMAG Rolling GmbH, Lamprechtshausnerstraße 61, 5282 Ranshofen, Austria;

E-Mails: gunther.rank@amag.at (G.R.); josef.berneder@amag.at (J.B.)

2 Institute of Nonferrous Metallurgy, Montanuniversität Leoben, Franz-Josef-Straße 18, 8700 Leoben, Austria; E-Mail: helmut.antrekowitsch@unileoben.ac.at

3 Laboratory of Metal Physics and Technology, Department of Materials, ETH Zurich, Vladimir-Prelog-Weg 4, 8093 Zürich, Switzerland; E-Mail: peter.uggowitzer@mat.ethz.ch

* Authors to whom correspondence should be addressed;

E-Mails: Ramona.Prillhofer@amag.at (R.P.); stefan.pogatscher@mat.ethz.ch (S.P.);

Tel.: +43-7722-8012-572 (R.P.); +41-44-6336-465 (S.P.);

Fax: +43-7722-8018-2572 (R.P.); +41-44-6331-421 (S.P.).

Received: 28 April 2014; in revised form: 13 June 2014 / Accepted: 24 June 2014 /

Published: 4 July 2014

\begin{abstract}
In this study, property criteria for automotive Al-Mg-Si sheet alloys are outlined and investigated in the context of commercial alloys AA6016, AA6005A, AA6063 and AA6013. The parameters crucial to predicting forming behavior were determined by tensile tests, bending tests, cross-die tests, hole-expansion tests and forming limit curve analysis in the pre-aged temper after various storage periods following sheet production. Roping tests were performed to evaluate surface quality, for the deployment of these alloys as an outer panel material. Strength in service was also tested after a simulated paint bake cycle of $20 \mathrm{~min}$ at $185^{\circ} \mathrm{C}$, and the corrosion behavior was analyzed. The study showed that forming behavior is strongly dependent on the type of alloy and that it is influenced by the storage period after sheet production. Alloy AA6016 achieves the highest surface quality, and pre-ageing of alloy AA6013 facilitates superior strength in service. Corrosion behavior is good in AA6005A, AA6063 and AA6016, and only AA6013 shows a strong susceptibility to intergranular corrosion. The results are discussed below with respect to the chemical composition, microstructure and texture of the Al-Mg-Si alloys studied, and decision-making criteria for appropriate automotive sheet alloys for specific applications are presented.
\end{abstract}


Keywords: Al-Mg-Si alloys; automotive sheets; formability; roping; corrosion

\section{Introduction}

Aluminum alloys have attracted considerable interest from the automotive industry in the last few years as manufacturers seek to design lightweight vehicles with improved fuel efficiency and reduced vehicle emissions. Heat treatable Al-Mg-Si alloys (6xxx series) are in particular increasingly used in automotive applications.

Materials for lightweight construction in automotive engineering must meet complex requirements, however. It is essential to combine good formability with high strength in service, excellent corrosion resistance and weldability [1]. For automotive body panels, additional decorative requirements must be met, which require a perfect material surface. Figure 1 summarizes and ranks the property criteria for Al-Mg-Si sheets for various automotive body-in-white applications, which are irrespective of the variants of $6 \times x x$ alloys $[2,3]$.

Figure 1. Property criteria for Al-Mg-Si sheet alloys for body-in-white applications [2,3].

\begin{tabular}{|l|c|c|c|c|}
\hline Criteria & $\begin{array}{c}\text { Outer skin } \\
\text { alloys }\end{array}$ & $\begin{array}{c}\text { Non decorative } \\
\text { inner alloys }\end{array}$ & $\begin{array}{c}\text { Structural } \\
\text { alloys }\end{array}$ & $\begin{array}{c}\text { Crash } \\
\text { alloys }\end{array}$ \\
\hline Formability & +++ & ++ & ++ & +++ \\
\hline Strength & ++ & ++ & +++ & +++ \\
\hline Surface quality & +++ & + & + & + \\
\hline Joinability & ++ & +++ & ++ & ++ \\
\hline Corrosion resistance & +++ & ++ & ++ & ++ \\
\hline Hemming & +++ & + & + & +++ \\
\hline
\end{tabular}

Heat-treatable alloys have the advantage of combining both good formability after solution-treatment and quenching and high strength after age hardening during the automotive paint bake process at $\sim 185{ }^{\circ} \mathrm{C}$. The paint bake process increases the strength of Al-Mg-Si alloys due to precipitation hardening and at the same time enables the curing of the paint [2].

Automotive engineers are demanding ever-higher strengths to generate greater potential for lightweight constructions. However, an increase in strength often involves a loss of ductility (formability). This is unsatisfactory for automotive designers, for whom excellent sheet product formability is a basic requirement, because automotive design must meet constantly increasing demands (e.g., sharp edges) [4]. Car manufacturers also require mechanical properties that remain stable for six months after solution heat treatment and quenching, to secure process stability during their forming operations. These conflicting needs must be balanced and require thorough knowledge of the interaction between material composition, production process and properties.

Silicon and magnesium are the main alloying elements of Al-Mg-Si alloys. In the last few years, several alloy modifications have been introduced to meet the requirements of car manufacturers. The 6xxx series alloys vary not only in their $\mathrm{Si} / \mathrm{Mg}$ ratio; they also differ in their transition element 
additions (e.g., $\mathrm{Cu}, \mathrm{Mn}, \mathrm{Fe}$ and V). Different compositions in combination with specific processing modifications produce a wide range of mechanical properties in the final products.

The present study compares four prominent Al-Mg-Si alloys (AA6016, AA6005A, AA6063 and AA6013) with regard to the requirements of the automotive industry and illustrates the wide property range generated by changes in chemical composition and process parameters. It concludes by evaluating a broad range of test results and proposing uses for the investigated alloys.

\section{Experimental Section}

\subsection{Alloy Production}

The chemical composition of the investigated Al-Mg-Si alloys is shown in Table 1. The industrial alloys were cast as ingots and then scalped on their rolling surface. For hot rolling, the alloys were heated up to typical rolling temperatures. After this heat treatment, the hot ingots were transferred to the rolling line. Then, the hot band was coiled and allowed to cool before it was cold rolled to the final gauge of $1 \mathrm{~mm}$. Solution treatment was performed in a continuous heat-treatment line, followed by subsequent water quenching. In addition to the simply quenched state (T4), a pre-ageing treatment $\left(100{ }^{\circ} \mathrm{C}\right.$ for $\left.5 \mathrm{~h}\right)$ was carried out directly after solution treatment [5-7]. Within this investigation, the temper produced in this way is called T4*. Temper T4 and especially the pre-aged temper T4* are typical states delivered to the automotive industry, which generally exhibit good forming performance. The final strength of the manufactured parts is achieved after forming operations and via the automotive paint bake cycle, which is simulated within this work by a heat treatment of $20 \mathrm{~min}$ at $185^{\circ} \mathrm{C}$ after $2 \%$ pre-straining. Temper T6 results from temper T4 followed by pre-straining for $2 \%$ and a heat treatment of 20 min at $185^{\circ} \mathrm{C}$. Temper $6^{*}$ is similar to $\mathrm{T} 6$, but started from the pre-aged temper T4* condition.

Table 1. Chemical composition of the investigated alloys.

\begin{tabular}{cccccccccc}
\hline Alloy & $\begin{array}{c}\text { Al } \\
(\mathbf{w t} \%)\end{array}$ & $\begin{array}{c}\mathbf{S i} \\
(\mathbf{w t} \%)\end{array}$ & $\begin{array}{c}\mathbf{F e} \\
(\mathbf{w t} \%)\end{array}$ & $\begin{array}{c}\mathbf{C u} \\
(\mathbf{w t} \%)\end{array}$ & $\begin{array}{c}\mathbf{M n} \\
(\mathbf{w t} \%)\end{array}$ & $\begin{array}{c}\mathbf{M g} \\
(\mathbf{w t} \%)\end{array}$ & $\begin{array}{c}\mathbf{C r} \\
(\mathbf{w t} \%)\end{array}$ & $\begin{array}{c}\mathbf{Z n} \\
(\mathbf{w t} \%)\end{array}$ & $\mathbf{S i} / \mathbf{M g}$ \\
\hline $\mathbf{A A 6 0 1 6}$ & Bal. & 1.03 & 0.17 & 0.08 & 0.08 & 0.32 & 0.01 & 0.01 & 3.2 \\
$\mathbf{A A 6 0 0 5 A}$ & Bal. & 0.81 & 0.19 & 0.04 & 0.17 & 0.50 & 0.01 & 0.01 & 1.6 \\
$\mathbf{A A 6 0 6 3}$ & Bal. & 0.64 & 0.19 & 0.02 & 0.02 & 0.55 & 0.01 & 0.02 & 1.4 \\
$\mathbf{A A 6 0 1 3}$ & Bal. & 0.75 & 0.27 & 0.75 & 0.50 & 0.98 & 0.01 & 0.02 & 0.8 \\
\hline
\end{tabular}

\subsection{Mechanical Properties}

Mechanical properties in tempers T4, T4*, T6 and T6* are evaluated by tensile tests in testing direction LT (long transverse) according to EN ISO 6892-1 $\left(\mathrm{L}_{0}=80 \mathrm{~mm}\right)$ [8]. The results of tensile tests are also of particular value for sheet metal forming operations. The tensile strain hardening exponent $n$ was measured in accordance with ISO 10275 [9], and the vertical anisotropy $r$ was determined in accordance with ISO 10113 [10] from tensile tests. To evaluate the plane anisotropy $\Delta r$, the $r$-values were also measured in testing direction $\mathrm{L}$, and $45^{\circ}$ and $\Delta r$ was calculated according to Equation (1).

$$
\Delta r=\frac{r_{90^{\circ}}+r_{0}^{\circ}}{2}-r_{45^{\circ}}
$$




\subsection{Forming Behavior}

\subsubsection{Forming Limit Curve (FLC)}

To describe the fundamental formability characteristics of the investigated sheet materials, a forming limit curve was carried out. The Nakazima test method was employed according to EN ISO 12004-2 (punch velocity: $1.5 \mathrm{~mm} / \mathrm{s}$; image rate: $15 \mathrm{~Hz}$ ) [11]. Therefore, wasted blanks with a parallel shaft to the rolling direction were used. The blanks had different widths: $20 \mathrm{~mm}, 50 \mathrm{~mm}, 80 \mathrm{~mm}, 100 \mathrm{~mm}$, $130 \mathrm{~mm}$ and a full-sized specimen.

\subsubsection{Bending Test}

Bending performance was characterized by a plane strain bending test according to VDA 238-100 (within this study, only bending in the L-direction was investigated) [12]. The test was performed on sheet metal strips with a length of $250 \mathrm{~mm}$ (in the LT-direction) and a width of $70 \mathrm{~mm}$ (in the L-direction). The metal strips were pre-strained for $10 \%$ in the LT-direction and afterwards machined into the bending test samples of $60 \times 60 \mathrm{~mm}^{2}$.

\subsubsection{Hole Expansion Test}

Hole expansion tests were conducted on an Erichsen 142/40, $400 \mathrm{kN}$ hydraulic sheet metal tester (Erichsen $\mathrm{GmbH} \& \mathrm{Co} \mathrm{KG}$, Hemer, Germany). Specimens for hole expansion testing were prepared and tested according to ISO 16630 [13]. The sheets were cut along the rolling direction into square specimens of $100 \times 100 \mathrm{~mm}^{2}$. A conical punch with a top angle of $60^{\circ}$ was used for hole-expansion purposes, and the initial hole was made by punching using a die diameter of $10 \mathrm{~mm}\left(d_{0}\right)$. The motion of the punch into the hole was stopped manually when a crack at the edge of the expanding hole was observed. The limiting hole expansion ratio $\lambda$ was then calculated according to Equation (2).

$$
\lambda=\frac{d_{h}-d_{0}}{d_{0}} \times 100
$$

In Equation (2) $d_{h}(\mathrm{~mm})$ is the average hole diameter after testing, and Figure 2 shows the die tool used for the hole-expansion test and a tested sample.

Figure 2. (a) Die tool used for the hole-expansion test; and (b) the final deformed part.

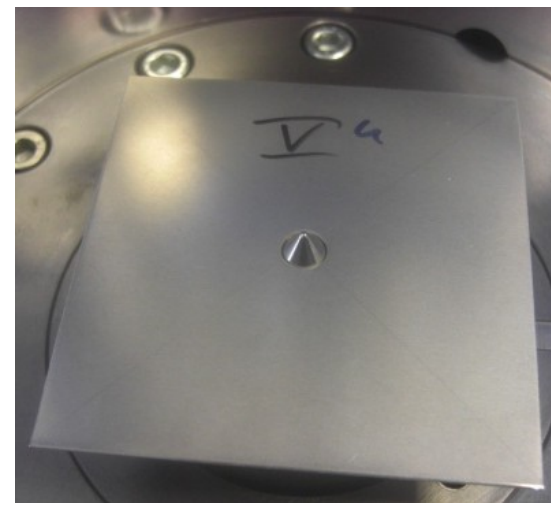

(a)

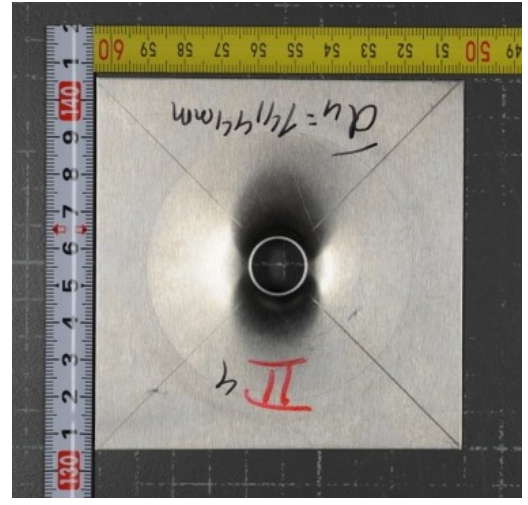

(b) 


\subsubsection{Cross-Die Test}

Cross-die tests are used for simulative testing by the automotive industry to evaluate the forming characteristics of sheet metals. Both the drawing height and the maximum strain, which can be sustained by the specimens before the onset of tearing, are delivered by the cross-die test. The experimental setup and the produced specimen are shown in Figure 3.

Figure 3. (a) Die tool used for the cross-die test; and (b) the final deformed part.

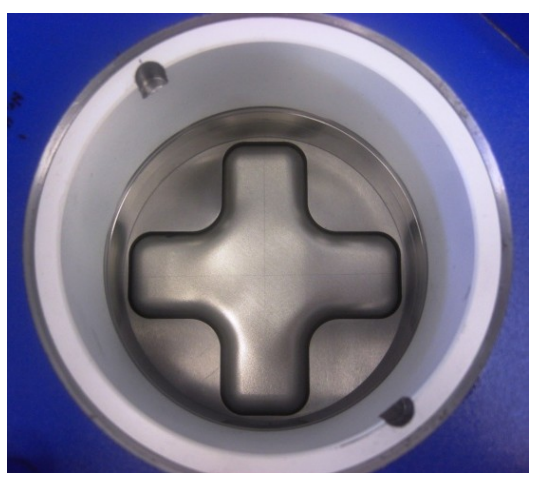

(a)

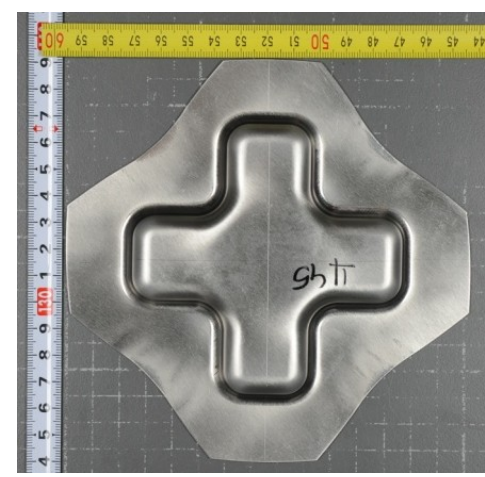

(b)

\subsection{Surface Quality}

Associated with automotive components are the deleterious surface defects referred to as roping, which appears on the surface of formed aluminum sheet components. Roping lines are present on the surface of the components as a series of closely spaced lines in the rolling direction (L). The roping lines appear in the rolling direction only when sufficient transverse strain is applied. For testing, a sample perpendicular to the rolling direction (LT) was stretched with a permanent elongation of $15 \%$ in a tensile testing machine (Zwick GmbH \& Co KG, Ulm, Germany). For systematic analysis, the sample was then painted black on both sides with a fine-pored sponge. Next, the sample was ground with P800 grade abrasive paper. The grinding process was carried out manually in the LT-direction at a low grinding pressure. After this procedure, any existing roping lines are clearly visible. To classify the samples in this respect, they were computer-scanned with a picture resolution of 300 dpi. Afterwards, the scanned pictures were imported into the image processing software Audi Roping Tool v.054 (Audi AG, Neckarsulm, Germany), which automatically calculates the roping grade with an inaccuracy of $\sim 10 \%$. The procedure and the classification criteria are illustrated in Figure 4.

\subsection{Corrosion Behavior}

Intergranular corrosion (IGC) testing was performed according to ISO 11846 method B [14]. In preparation, samples were etched twice: for $90 \mathrm{~s}$ in hot caustic soda solution and for $60 \mathrm{~s}$ in a hydrofluoric acid containing etching solution, as described in the standard. The classification criteria for this test method are shown in Table 2. Samples were immersed for $24 \mathrm{~h}$ at $30{ }^{\circ} \mathrm{C}$ in a solution containing $30 \mathrm{~g} / \mathrm{L} \mathrm{NaCl}$ and $10 \mathrm{~mL}$ concentrated hydrochloric acid. The type and depth of the corrosion attack were evaluated by an optical microscope on $30 \mathrm{~mm}$-long metallographic cross-sections longitudinal to the rolling direction. 
Figure 4. Roping test procedure rating.

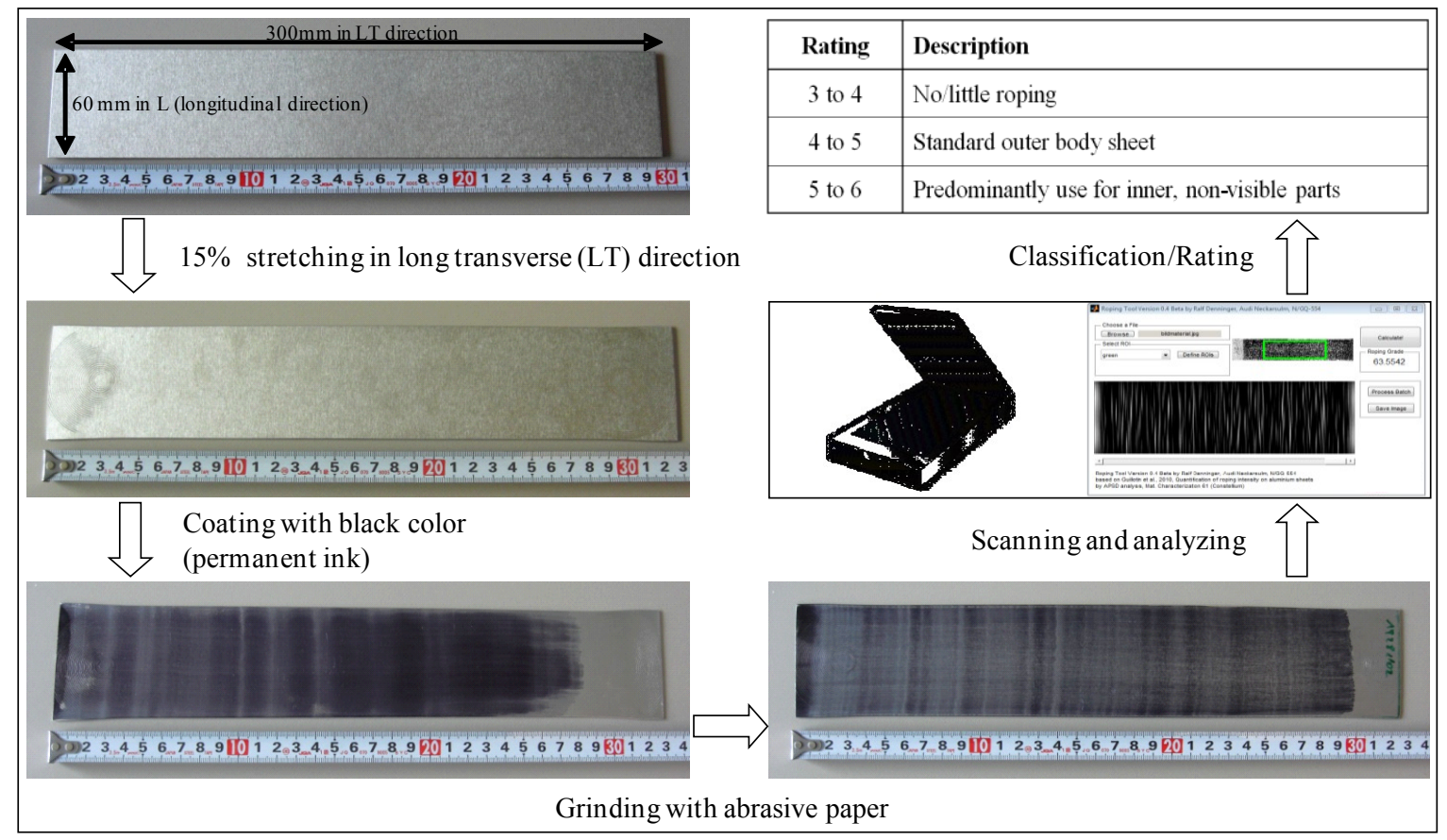

Table 2. Classification of intergranular corrosion. IGC, intergranular corrosion; $\mathrm{PC}$, pitting corrosion.

\begin{tabular}{ccc}
\hline Grade & Type of Corrosion & Acronym \\
\hline 1 & Pitting corrosion & PC \\
2 & Pitting and intergranular corrosion (dominant PC) & PC/IGC \\
3 & Intergranular and pitting corrosion (dominant IGC) & IGC/PC \\
4 & Intergranular corrosion: local & IGC4 \\
5 & Intergranular corrosion: quasi area-wide & IGC5 \\
\hline
\end{tabular}

\subsection{Microstructure Observation}

Samples for scanning electron microscopy (SEM) and energy dispersive X-ray spectroscopy (EDX) were prepared by mechanical grinding and polishing. SEM characterization of the microstructure was done by a Zeiss EVO 40 microscope (Carl Zeiss GmbH, Jena, Germany) equipped with a tungsten cathode and employing an acceleration voltage of $15 \mathrm{kV}$ and a working distance of 6 to $8 \mathrm{~mm}$. The chemical composition of the constituents was determined by EDX on polished surfaces of the samples. For light optical micrographs, an Olympus AHMT-3 microscope (Olympus GmbH, Hamburg, Germany) was used.

\section{Results}

\subsection{Mechanical Properties}

Figure 5 shows the yield strength $\left(R_{\mathrm{p} 0.2}\right)$ in temper T4* after different storage periods following sheet production. In general, the yield strength increases with storage at RT. AA6013 exhibits the highest $R_{\mathrm{p} 0.2}$ of $185 \mathrm{MPa}$ in temper T4* after one month after sheet production. The yield strength of 
AA6013 increases over six months from 185 to $200 \mathrm{MPa}$. In contrast, AA6063 shows the lowest $R_{\mathrm{p} 0.2}$ of $90 \mathrm{MPa}$ after brief room temperature storage, but exhibits the highest overall strength increase over the storage time. The yield strength of AA6016 stays nearly constant after three months and shows the smallest overall increase when stored at RT.

Figure 5. Yield tensile strength $R_{\mathrm{p} 0.2}$ in temper T4* measured one, three and six months after sheet production (LT-direction).

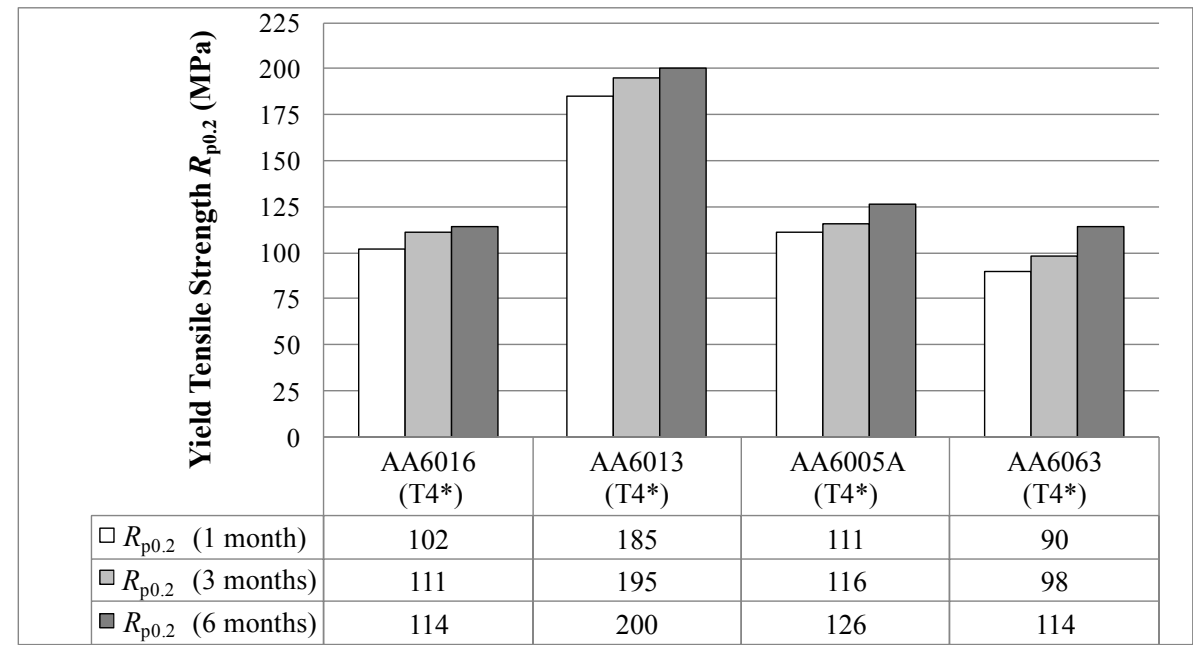

Figure 6 summarizes the mechanical properties of the investigated alloys after pre-aging and the simulated paint bake process (termed $\mathrm{T} 6^{*}$ ). The achieved yield strength decreases with increasing storage time. This was observed for all alloys except AA6013, which showed a slight increase in strength over time. It was found that AA6005A generates a superior yield strength of $223 \mathrm{MPa}$ after a six months storage time in comparison to AA6016 and AA6063. Overall, AA6013 exhibits the highest yield strength of $275 \mathrm{MPa}$ after one month of storage. Ultimate tensile strength results are also shown in Figure 6, as these values are of interest for the materials in service. However, the general trends among the alloys appear to be similar.

Figure 6. Yield tensile strength $R_{\mathrm{p} 0.2}$ and ultimate tensile strength $R_{\mathrm{m}}$ in temper T6* measured one, three and six months after sheet production (LT-direction).

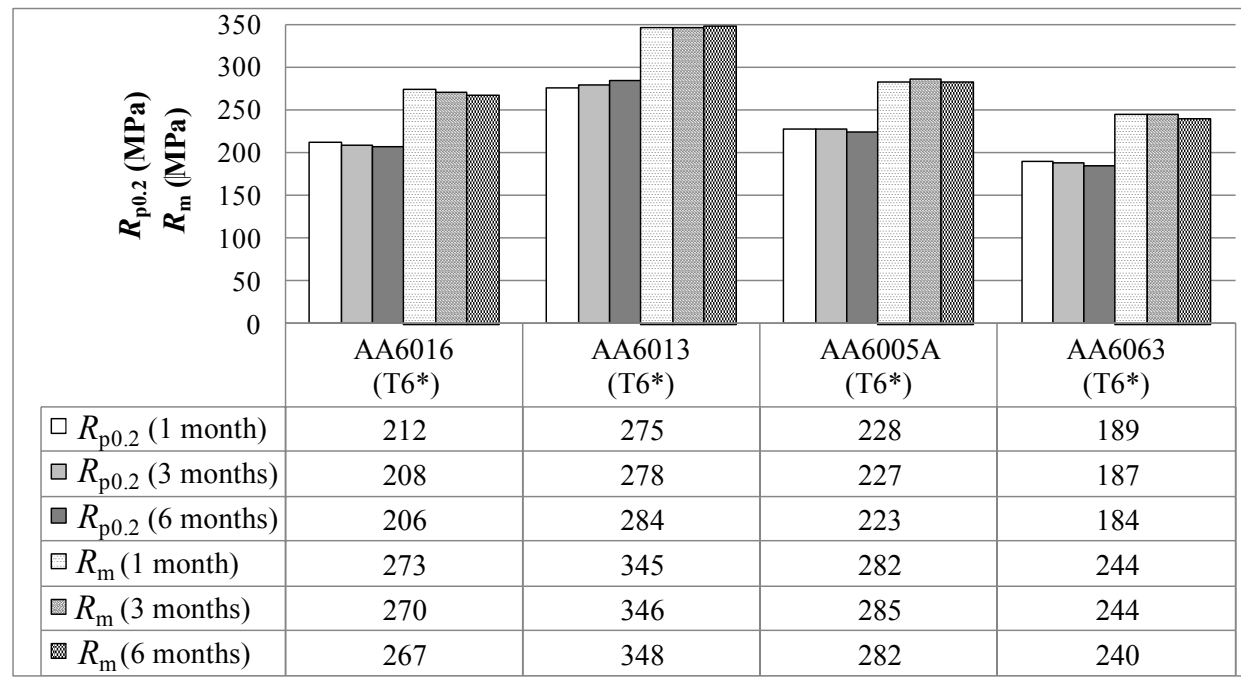


In order to show the influence of pre-aging on mechanical properties, Figure 7 illustrates the yield strength and ultimate tensile strength of alloy AA6016 for temper T4 (without pre-aging) and temper T4* (with pre-aging) after one month of storage and in the resulting tempers T6 and temper T6*, respectively. T4 values are generally higher than temper $\mathrm{T} 4^{*}$, and a simulated paint bake process produces a more pronounced increase in strength after pre-aging.

Figure 7. Yield tensile strength $R_{\mathrm{p} 0.2}$ and ultimate tensile strength $R_{\mathrm{m}}$ in tempers $\mathrm{T} 4, \mathrm{~T} 4^{*}$, T6 and T6* measured one month after sheet production (LT-direction).

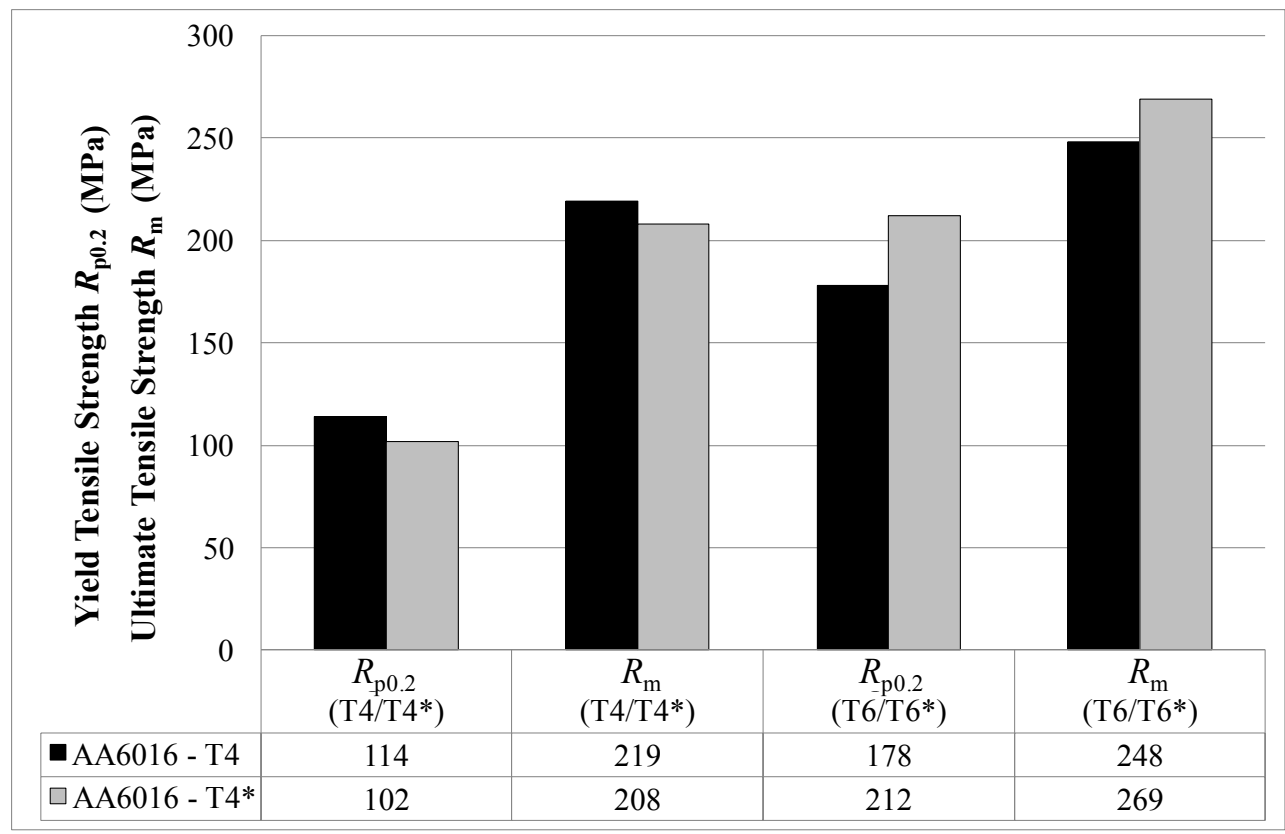

Figure 8 illustrates the total elongation $A_{80}$ of the investigated alloys. AA6016 reaches the highest elongation value of nearly $26 \%$ after six months of storage time. AA6013 exhibits the lowest elongation. The results show only small changes over storage time for all of the alloys.

Figure 8. Total elongation $A_{80}$ in temper T4* measured one, three and six months after sheet production (LT-direction).

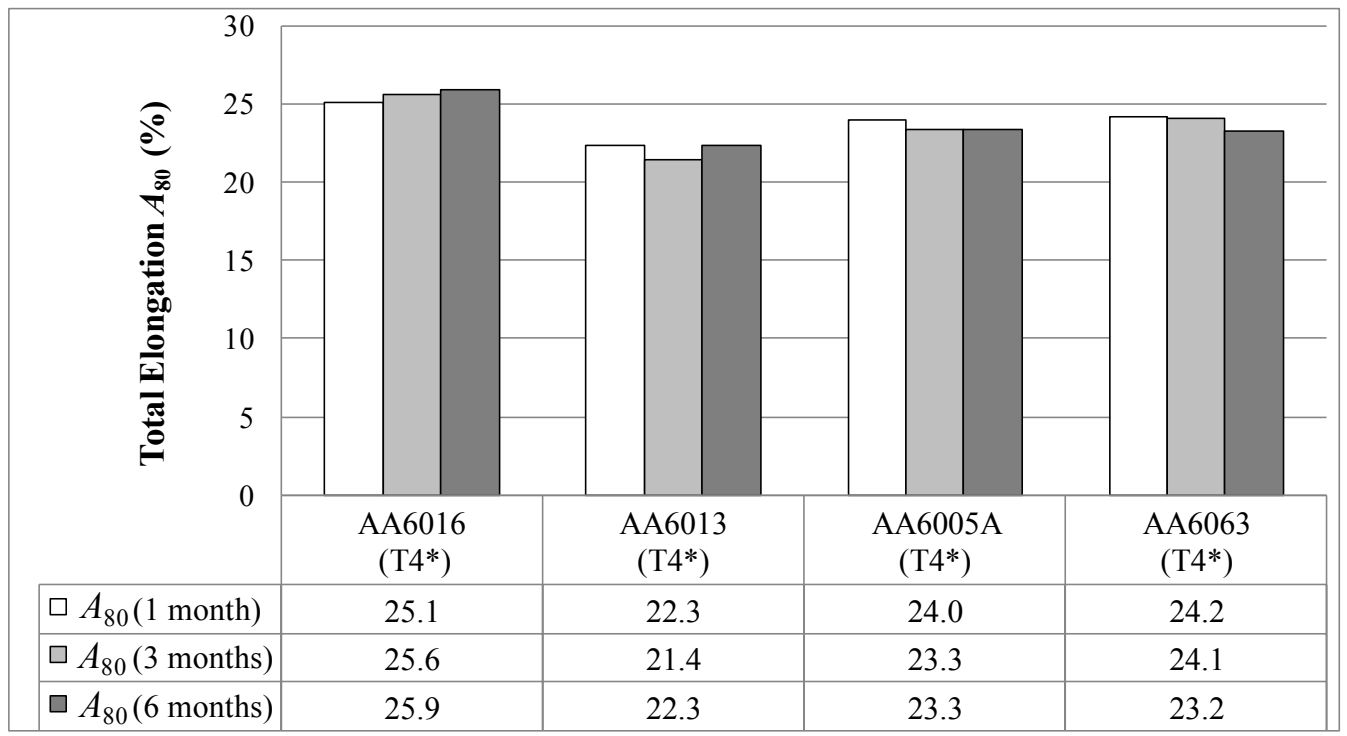


Figure 9 shows the vertical anisotropy $r$, the plane anisotropy $\Delta r$, the strain hardening exponent $n$ and the yield ratio $R_{\mathrm{p} 0.2} / R_{\mathrm{m}}$ for a storage period of one month after sheet production for the investigated alloys as deduced from tensile tests. All shown values are nearly constant after one month of storage. AA6005A and AA6063 reach a high $r$-value in $90^{\circ}$, but the plane anisotropy of these alloys is high, which means that the forming behavior is not uniform in all rolling directions $\left(0^{\circ}, 45^{\circ}\right.$ and $\left.90^{\circ}\right)$. AA6016 provides a relatively low $\Delta r$-value of 0.28 and shows the highest $n$-value of 0.30 of all of the alloys. AA6013 exhibits the most uniform $r$-value in all rolling directions, with a plane anisotropy of zero. The yield ratios $R_{\mathrm{p} 0.2} / R_{\mathrm{m}}$ of the investigated alloys are nearly identical, with the exception of AA6013, which shows a comparably high yield ratio of 0.59 .

Figure 9. Vertical anisotropy $r$ (LT), strain hardening exponent $n$ (LT), plane anisotropy $\Delta r$ (according Equation (1)) and $R_{\mathrm{p} 0.2} / R_{\mathrm{m}}$ ratio (LT) in temper $\mathrm{T} 4 *$ measured one month after sheet production.

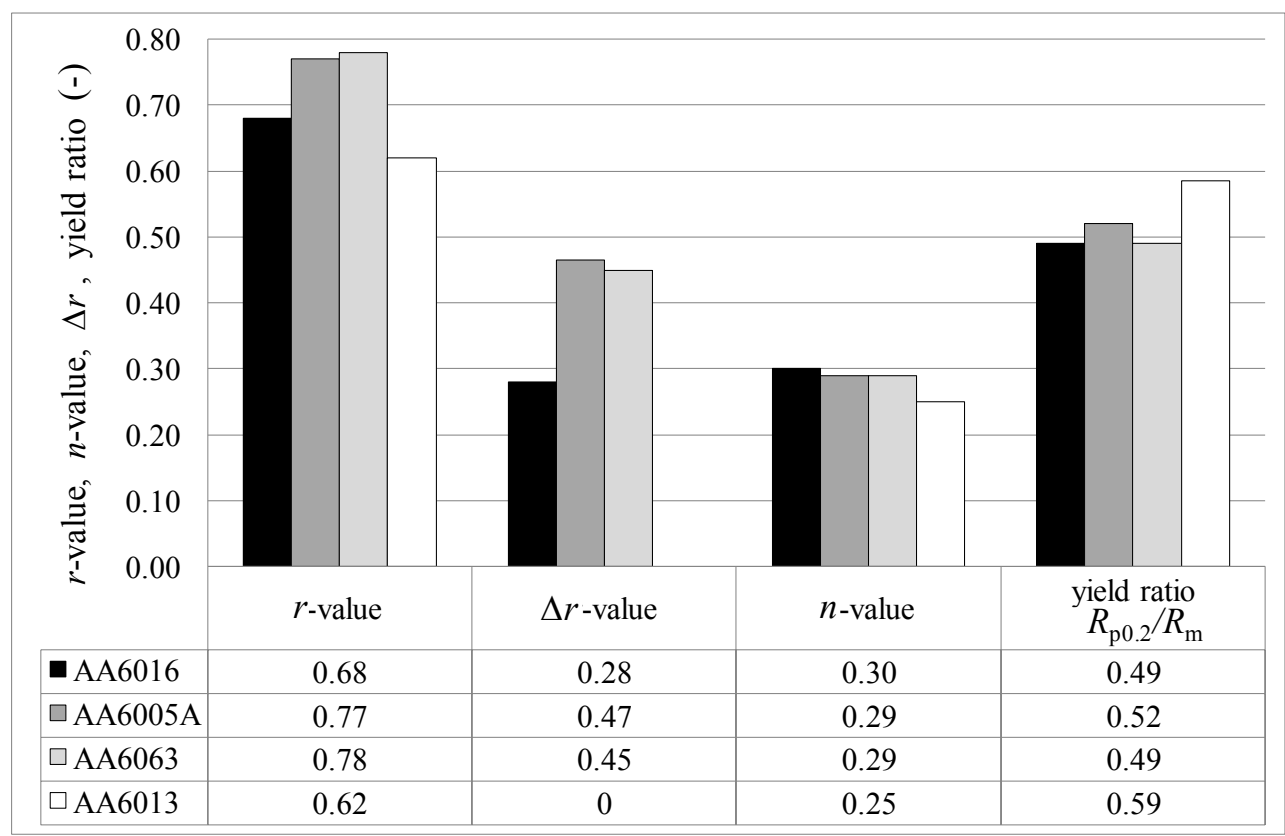

\subsection{Forming Behavior}

\subsubsection{Forming Limit Curve (FLC)}

Figure 10 shows that AA6063 allows the greatest deformation before the first failures occur, and that the forming limit curves (FLCs) of AA6013 and AA6005 appear to be rather similar at lower strain values. The FLC of AA6016 lies between those of the other alloys.

Figure 11a-d illustrates the forming limit curves of the investigated alloys as a function of room temperature storage time. The curves were measured two and six months after sheet production. The FLC of the tested alloys show only a weak decrease due to storage at RT. Alloy AA6063 showed the strongest deviation between two and six months of storage time. 
Figure 10. Forming limit curves of AA6016, AA6005A, AA6063 and AA6013 in temper T4* for a sheet thickness of $1.0 \mathrm{~mm}$ measured two months after sheet production.

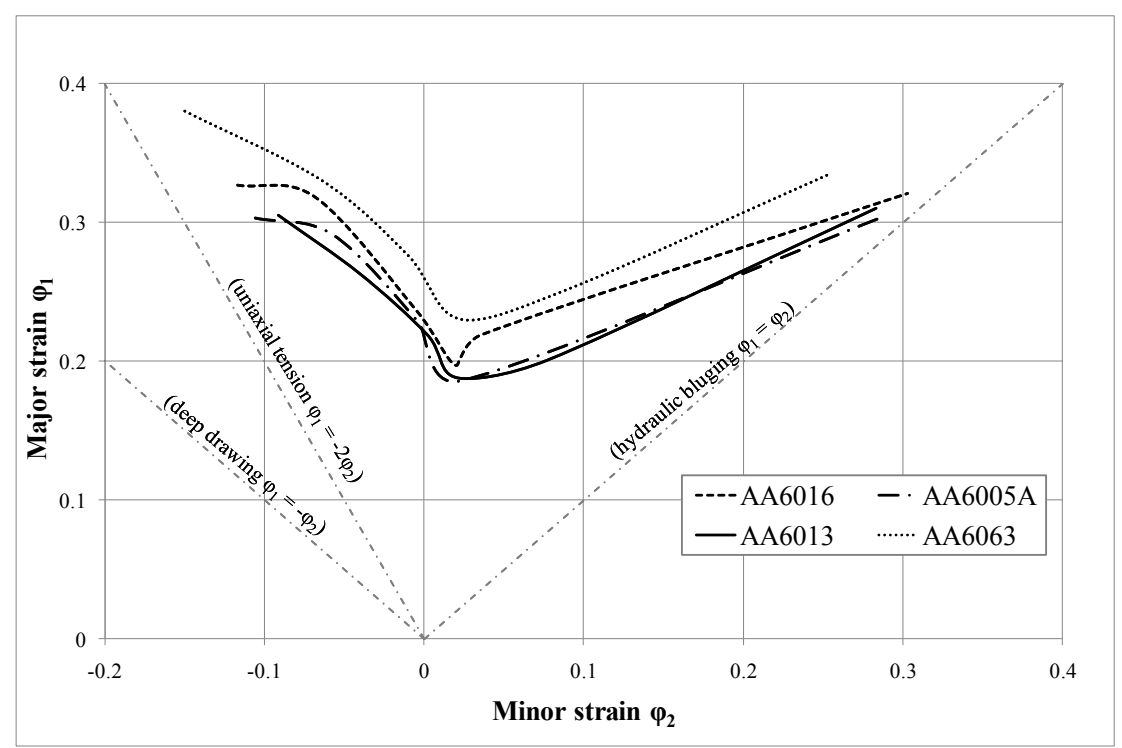

Figure 11. Forming limit curve of (a) AA6016; (b) AA6005A; (c) AA6063; (d) AA6013 in temper $\mathrm{T} 4 *$ for a sheet thickness of $1.0 \mathrm{~mm}$ measured two and six months after sheet production.

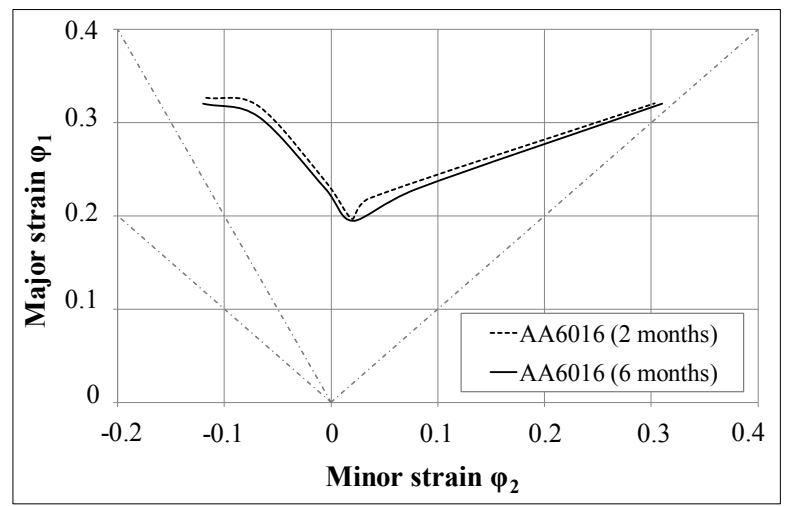

(a)

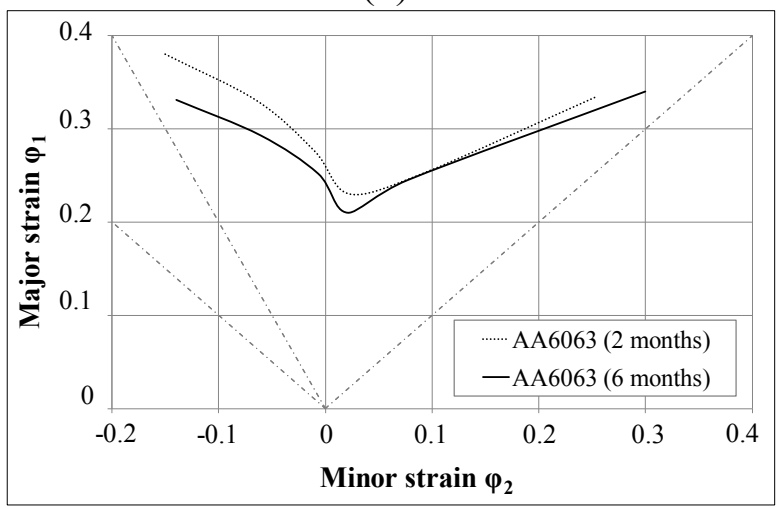

(c)

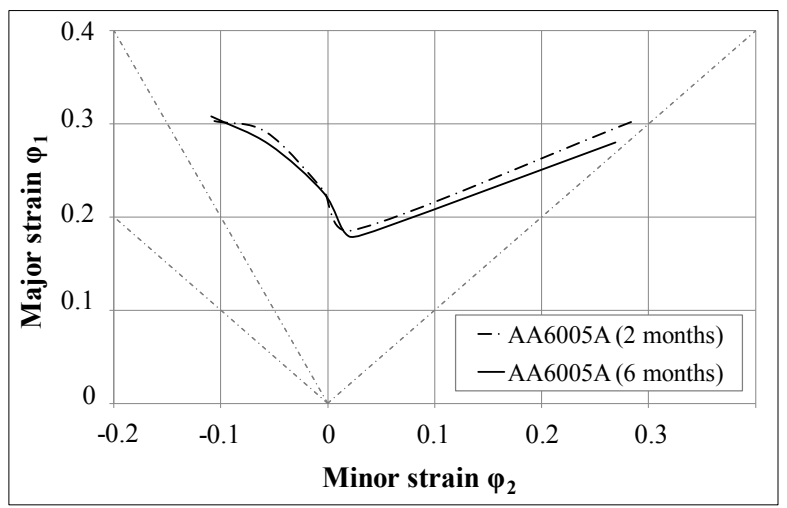

(b)

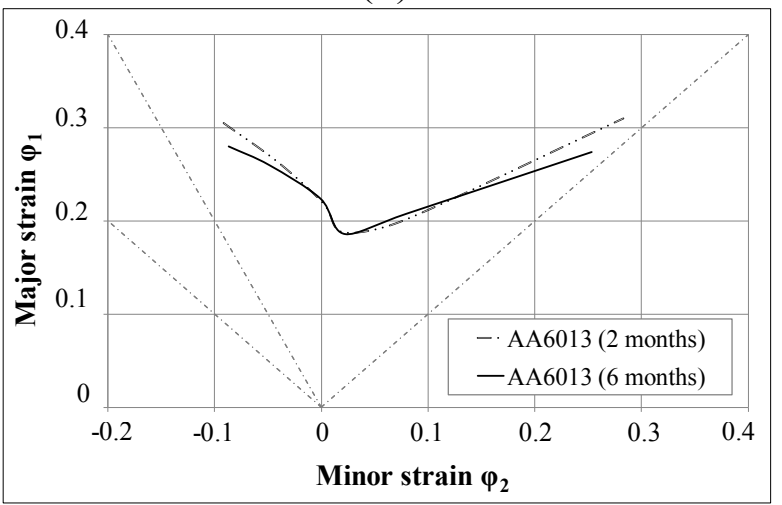

(d) 


\subsubsection{Bending Performance}

Table 3 depicts the bending results for the investigated material after different storage periods. AA6016 and AA6063 exhibit the best bending performance, with a bending angle of nearly $150^{\circ}$ even after six months of storage at RT. In contrast, AA6013 shows the weakest bending performance with a bending angle of around $80^{\circ}$. It was found that the bending performance of AA6016 stays nearly constant at the value reached after three months' natural ageing, whereas the bending behavior of AA6063 shows a more pronounced dependence on RT storage.

Table 3. The bending angle (in ${ }^{\circ}$ ) measured one, three and six months after sheet production in temper $\mathrm{T} 4 *$.

\begin{tabular}{ccccc}
\hline \multirow{2}{*}{ Age } & \multicolumn{4}{c}{ Bending Angle $\left(^{\circ}\right.$ ) of different alloys } \\
\cline { 2 - 5 } & AA6016 & AA6005A & AA6063 & AA6013 \\
\hline 1 month & 156 & 134 & 159 & 84 \\
3 months & 152 & 128 & 155 & 83 \\
6 months & 151 & 126 & 147 & 77 \\
\hline
\end{tabular}

\subsubsection{Hole-Expansion Test}

Table 4 lists the limiting hole-expansion ratio $\lambda$ of the investigated alloys for various storage periods. Alloys AA6016, AA6005A and AA6063 show nearly the same results with a ratio $>50 \%$. Alloy AA6013 reaches the lowest hole-expansion ratio, around $41 \%$. The results show only slight changes over storage time for all alloys, but by a trend, the hole expansion ratio decreased with RT storage.

Table 4. Limiting hole-expansion ratio (in \%) measured one, three and six months after sheet production in temper T4*.

\begin{tabular}{ccccc}
\hline \multirow{2}{*}{ Age } & \multicolumn{4}{c}{ Limiting hole expansion ratio $\boldsymbol{\lambda}$ (\%) of different alloys } \\
\cline { 2 - 5 } & $\mathbf{A A 6 0 1 6}$ & $\mathbf{A A 6 0 0 5}$ & $\mathbf{A A 6 0 6 3}$ & $\mathbf{A A 6 0 1 3}$ \\
\hline 1 month & 53.0 & 56.7 & 52.3 & 41.6 \\
3 months & 52.3 & 55.3 & 52.7 & 42.0 \\
6 months & 52.0 & 55.3 & 51.3 & 41.3 \\
\hline
\end{tabular}

\subsubsection{Cross-Die Test}

Before the experimental test was carried out, a simulation was performed to predict where and at what forming height the first cracks can be expected. The simulation result was verified to agree well with the experiment. The first cracks occur due to thinning in the corners of the formed cross (Figure 12b illustrates this in blue). Due to thinning, the material thickness decreased in this case from $1.1 \mathrm{~mm}$ to $0.7 \mathrm{~mm}$. In this area, the material is mainly stretched under biaxial tension.

The forming height of the investigated alloys is given in Table 5 as a function of storage time. It was found that alloys AA6005 and AA6016 achieve the best results in this test at a forming height of around $18 \mathrm{~mm}$, whereas AA6013 only reaches a height of around $15 \mathrm{~mm}$. The results showed a slight decrease in height with increasing storage time. 
Figure 12. The appearance of a crack due to thinning on the corners of the cross-die sample: (a) experiment and (b) simulation of the material thinning in ( $\mathrm{mm}$ ).

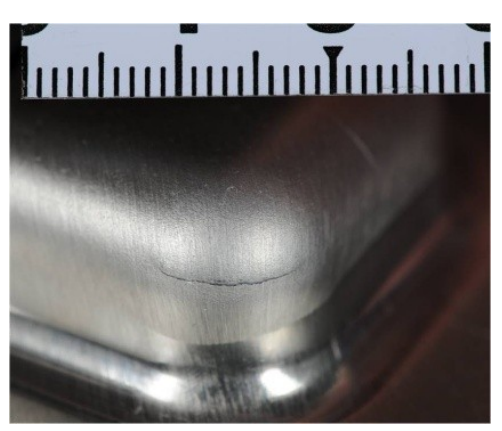

(a)

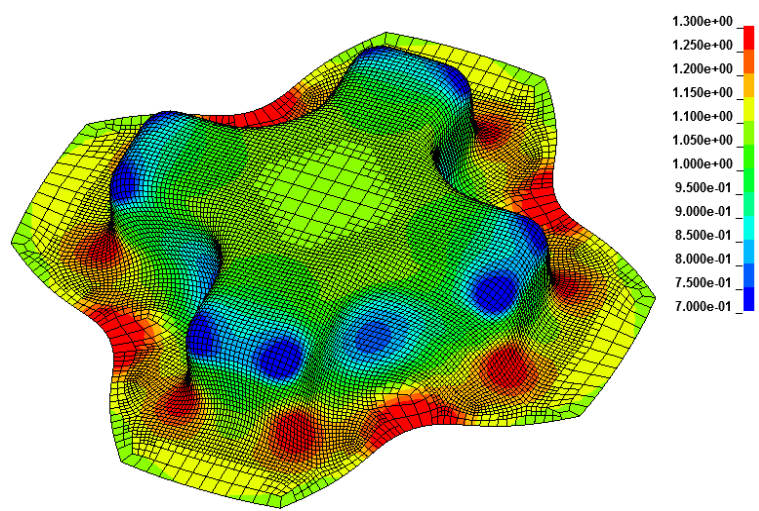

(b)

Table 5. Cross-die forming height (in $\mathrm{mm}$ ) measured one, three and six months after sheet production in temper T4*.

\begin{tabular}{ccccc}
\hline \multirow{2}{*}{ Age } & \multicolumn{4}{c}{ Cross-die forming height different alloys (mm) } \\
\cline { 2 - 5 } & AA6016 & AA6005A & AA6063 & AA6013 \\
\hline 1 month & 18.2 & 18.4 & 17.9 & 15.3 \\
3 months & 18.1 & 18.2 & 17.2 & 15.0 \\
6 months & 18.2 & 17.9 & 16.6 & 14.7 \\
\hline
\end{tabular}

\subsubsection{Surface Quality}

Figure 13 illustrates roping test samples after tests on a material with low (Figure 13a) and high roping sensitivity (Figure 13b).

Figure 13. Roping behavior: (a) no/little roping; (b) clearly visible roping.

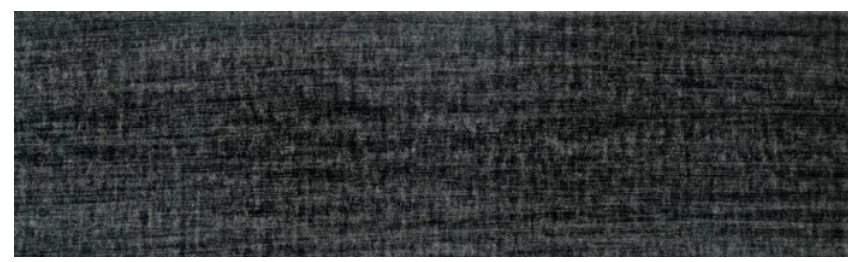

(a)

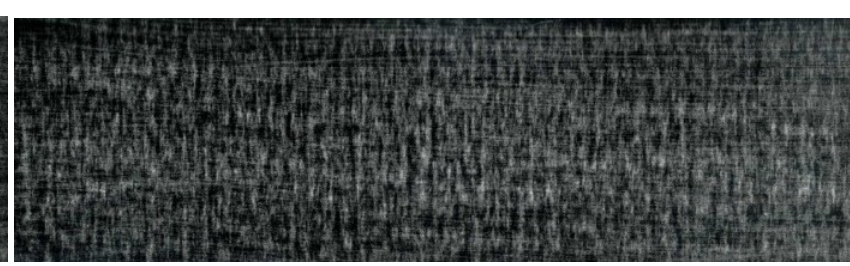

(b)

Table 6 summarizes the results of the roping test. The roping behavior was analyzed after different storage periods, but storage does not influence the classification. It was found that AA6016 generates the best roping result with a rating of 3.8 (no/little roping), followed by AA6005A and AA6063. Only AA6013 reaches an insufficient value (5.4).

Table 6. Classification of the roping test samples.

\begin{tabular}{ccccc}
\hline \multirow{2}{*}{ Classification } & \multicolumn{4}{c}{ Classification rating of different alloys } \\
\cline { 2 - 5 } & AA6016 & AA6005A & AA6063 & AA6013 \\
\hline Roping behavior & 3.8 & 4.2 & 4.5 & 5.4 \\
\hline
\end{tabular}




\subsubsection{Corrosion Behavior}

Table 7 and Figure 14 present the corrosion test results for the investigated material. Testing was performed on samples that were naturally aged for one month. AA6016 exhibits IGC (see Table 4 for corrosion modes) with a maximum corrosion depth of $150 \mu \mathrm{m}$ in temper T4* (Figure 14a). Alloys AA6005A and AA6063 are nearly unaffected in temper T4*. Only a few attacks can be observed in the surface region, as shown in Figure 14c,e. AA6013 shows PC (pitting corrosion) in temper T4* with a maximum depth of $50 \mu \mathrm{m}$ (Figure $14 \mathrm{~g}$ ). Different behavior was seen in condition T6*. After the simulated paint bake treatment, AA6013 exhibits IGC with a corrosion depth of $350 \mu \mathrm{m}$ (Figure 14h). AA6016 was also found to be susceptible to IGC in temper T6*, but with a more moderate maximum corrosion depth of $180 \mu \mathrm{m}$ (Figure 14b). However, AA6005A and AA6063 show no attack in the T6* temper (Figure 14d,f).

Table 7. Classification of corrosion behavior in temper T4* and temper T6*.

\begin{tabular}{ccccc}
\hline Sample & Alloy & Temper & Type of corrosion & Depth $(\boldsymbol{\mu m})$ \\
\hline a & AA6016 & T4* & IGC, Grade 5 & 150 \\
c & AA6005A & T4* & Low IGC/PC, Grade 3 & 30 \\
e & AA6063 & T4* & Low IGC, Grade 4 & 15 \\
g & AA6013 & T4* & PC, Grade 1 & 50 \\
b & AA6016 & T6* & IGC, Grade 5 & 180 \\
d & AA6005A & T6* & No attack & 0 \\
f & AA6063 & T6* & No attack & 0 \\
h & AA6013 & T6* & IGC, Grade 5 & 350 \\
\hline
\end{tabular}

Figure 14. Corrosion behavior in temper T4* and temper T6*. (a) AA6016-1.10 mm-T4*; (b) AA6016-1.10 mm-T6*; (c) AA6005A-1.00 mm-T4*; (d) AA6005A-1.00 mm-T6*; (e) AA6063-1.15 mm-T4*; (f) AA6063-1.15 mm-T6*; (g) AA6013-1.02 mm-T4*; (h) AA6013-1.02 mm-T6*.

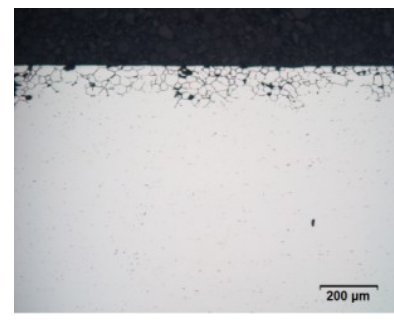

(a)

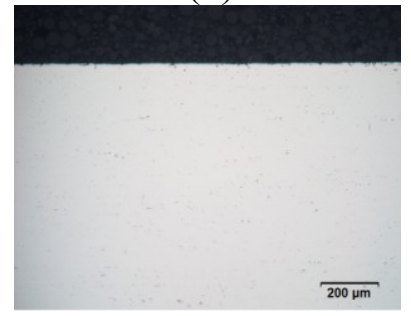

(e)

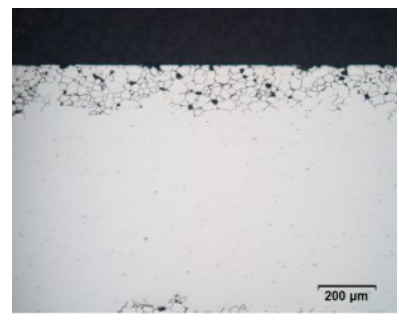

(b)

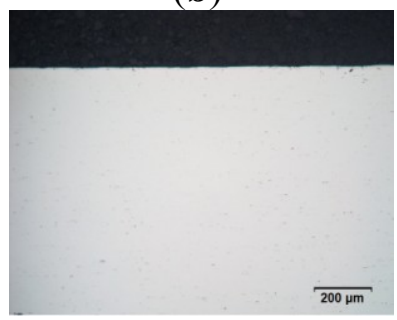

(f)

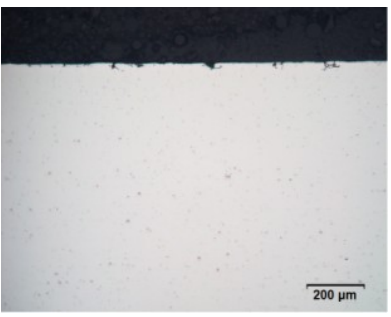

(c)

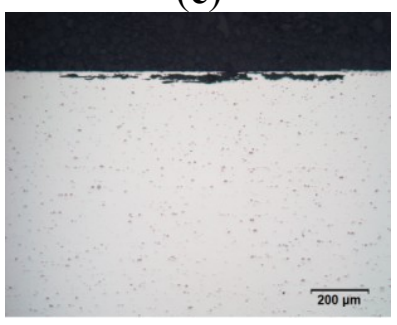

(g)

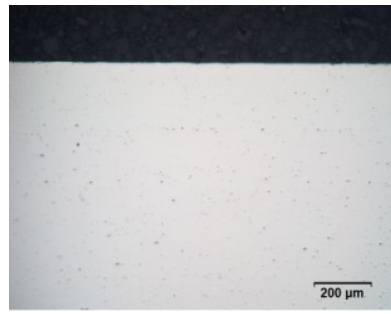

(d)

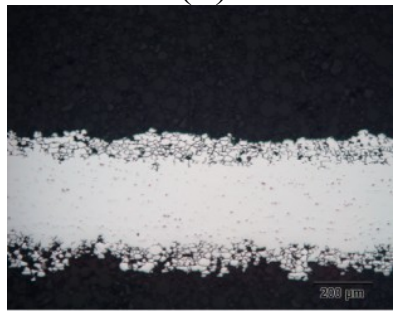

(h) 


\section{Discussion}

\subsection{Mechanical Properties}

In general, solution heat-treated and quenched tempers are non-stable tempers. Strength increases with storage time due to natural ageing, and this is attributed to the clustering of solute atoms $(\mathrm{Mg}, \mathrm{Si}$ and also $\mathrm{Cu}$, if contained in the alloys) [15]. Pre-aging treatments can decrease hardening during natural ageing (clustering) due to a decrease of the concentration of quenched-in vacancies and the formation of larger clusters [16,17]. This explanation is assumed to be the reason why the initial strength level of T4 is higher than for T4* (see Figure 7). However, further atom probe analysis would be necessary to explain this more precisely.

Pre-aging has been shown to reduce the effect of natural ageing, but it cannot be fully prevented during RT storage (see Figure 5). The automotive industry must ensure quality restrictions for at least six months. Within this period, mechanical properties must remain within the specification limits and variations should be as low as is physically possible. For this purpose, the most "stable" of our alloys is AA6016 (in terms of absolute values), which does not change its yield strength significantly upon long-term storage (Figure 5).

The 6xxx series aluminum alloys are characterized by their main alloying elements, $\mathrm{Si}$ and $\mathrm{Mg}$, and the additions of $\mathrm{Cu}, \mathrm{Mn}$ and $\mathrm{Fe}$. As Table 2 shows, the alloys studied exhibit different $\mathrm{Si} / \mathrm{Mg}$ ratios. AA6016 shows the highest and, in consequence, also a high amount of Si in excess of the equilibrium precipitate phase $\mathrm{Mg}_{2} \mathrm{Si}$ [18], which forms in Al-Mg-Si alloys. It is known that a high $\mathrm{Si} / \mathrm{Mg}$ ratio produces an increased strengthening coefficient, which improves the formability of the alloy [19]. This effect was also observed in the present study. Accordingly, AA6016 reaches the highest $n$-value, whereas AA6013, which exhibits a higher amount of $\mathrm{Mg}$ than $\mathrm{Si}$, exhibits a lower $n$-value (Figure 9). Due to the observed lower elongation of AA6005A and AA6063 in comparison to AA6016, a lower $\mathrm{Si} / \mathrm{Mg}$ ratio may also generate lower elongation values (Figure 8).

Alloy AA6013 was found to exhibit better strength levels than the other alloys in tempers T4* and T6*. This is simply because of its chemical composition. Adding copper to Al-Mg-Si alloys refines the precipitate structure, induces the strengthening phase Q' (Cu-containing phase) and, therefore, increases the strength level [20]. The relatively high Mn-content in AA6013 was also shown to increase its initial strength, presumably due to solid solution hardening [21]. In contrast, AA6063 provides the lowest strength, both in tempers $\mathrm{T} 4 *$ and in $\mathrm{T} 6 *$. This alloy contains nearly no $\mathrm{Cu}$ and $\mathrm{Mn}$, and the $\mathrm{Mg}$ and Si content is also comparably low.

The higher T6* strength of alloy AA6005A compared to AA6063 can be dedicated to its higher content of hardening elements. Although the amount of $\mathrm{Mg}+\mathrm{Si}$ is comparable in AA6005 and AA6016, AA6005 offers a higher T6* strength. This might be related to its well-balanced Si/Mg ratio. It is assumed that because of the close compositional relationship between alloy AA6005 and the major hardening precipitate (probably $\beta^{\prime \prime}=\mathrm{Mg}_{5} \mathrm{Si}_{6}$ [22]), a higher number density is formed, which, in turn, generates higher strength in $\mathrm{T}^{*}$ temper [23]. Note that the paint bake response of the investigated alloys is better if pre-ageing was carried out directly after solution annealing (compare T6 and $\mathrm{T}^{*}$ in Figure 7). It is assumed that the $\mathrm{Mg}, \mathrm{Si}$ clusters formed during the pre-aging with subsequent natural aging exceed a critical size, which makes them more stable than those in the naturally 
aged T4 state [24]. The stable clusters can act as nuclei for the $\beta^{\prime \prime}$ precipitation during subsequent artificial aging and, therefore, enhance the artificial aging kinetics [16]. We have discussed T4* and T6* tempers in more detail than tempers $\mathrm{T} 4$ and $\mathrm{T} 6$, because $\mathrm{T} 4^{*}$ and $\mathrm{T} 6^{*}$ are more important conditions for future applications.

Anisotropy plays an important role during forming processes and can lead to earing during deep drawing. Some characteristics of anisotropy can already be deduced from tensile tests, as shown in Section 3.1. Materials with a high vertical anisotropy $r$-value possess high resistance to plastic flow in the direction of the sheet thickness. The strain-hardening exponent $n$ can be considered as an indicator of the maximum attainable deformation during cold forming. The higher the $n$-value and, consequently, the higher the uniform strain, the lower the tendency of the material to neck locally. AA6013 shows the most uniform $r$-value in all rolling directions, with a plane anisotropy of zero (Figure 9). Normally the $r$-value in the $45^{\circ}$ direction is much lower than the values for $0^{\circ}$ and $90^{\circ}$ in Al-Mg-Si alloys, but AA6013 exhibits a very high $r$-value at $45^{\circ}$ to the rolling direction of 0.78 . Because $r$-values correlate with the rolling texture, it can be assumed that the high $\mathrm{Cu}$-content and the low $\mathrm{Si} / \mathrm{Mg}$ ratio in AA6013 influence the rolling texture positively. Further, texture investigations would be necessary to address this result more precisely.

\subsection{Formability}

Using forming limit curves (illustrated for the investigated alloys in the T4* temper in Figures 10 and 11), it is possible to determine process limitations in sheet metal forming in the case of a linear strain path (e.g., necking and tearing). AA6063 provides the most promising FLC, which is presumably related to its lower strength level and lower amount of main alloying in comparison to the other alloys (Figure 5). Although AA6013 shows the highest strength during tensile testing (Figure 5), the FLC is almost comparable to AA6005A. A detailed explanation of this result is outside the scope of this paper, but a correlation with the very low plane anisotropy $\Delta r$ of AA6013 (due to the high $r$-value at $45^{\circ}$ ) is assumed. In general, FLCs are not strongly influenced by RT storage after sheet production, which is a rather satisfying result in view of the requirements of the automotive industry (Figure 11). However, alloy AA6063 showed the strongest, though moderate, influence of storage, which can be related to the yield strength increase upon storage, which was also highest for AA6063 (Figure 5).

In addition to the Nakazima tests (FLC), hole-expansion tests, bending tests and deep-drawing tests in a cross-die were conducted to characterize the forming behavior of the materials investigated in this study. Test procedure limitations make it necessary to carry out more than one forming test to analyze the formability of a sheet metal and to predict its behavior during industrial forming processes.

Hemming is a typical assembly method used in the automotive industry to join the outer sheet to the inner part of hang-on body panels. The requirements on an alloy that is subjected to hemming are tough, because the material has to withstand strong bending over a radius equal to half of the sheet thickness. Therefore, high aluminum sheet bendability is a desirable property in the production of an automotive body panel. It has been shown that a high yield strength in temper T4* generates low bendability $[25,26]$. Failure during bending of Al-Mg-Si alloys can occur through intergranular fracture due to the presence of grain boundary particles [27]. Strain localization and intense shearing in relation to micro-void formation around large phase particles can also cause fracture during 
bending [28]. AA6016 and AA6063 showed the best bending performance (they exhibit the lowest $R_{\mathrm{p} 0.2}$ in T4*; see Figure 5) compared to AA6005A and AA6013 (Table 3). The poor bending performance of AA6013 may be related, on the one hand, to its $\mathrm{Cu}$-content: copper tends to form grain boundary precipitates. On the other hand, large intermetallic particles can also influence the bendability negatively [19]. Industrially produced $\mathrm{Al}-\mathrm{Mg}$-Si alloys always contain iron. This governs the formation of intermetallic Al-Fe-Si-(Mn) particles, which influence the formability negatively. In Al-Mg-Si alloys, $\beta$-AlFeSi and $\alpha$-AlFeSi particles are mainly present. These particles form during solidification and homogenization of as-cast ingots and do not dissolve when the alloy is further heat-treated. The $\alpha$-particles have a more globular morphology than the plate-like $\beta$-particles, which are known to promote the formation of voids during deformation [29-32]. AA6013 and AA6005A contain more $\mathrm{Fe}$ and $\mathrm{Mn}$, which also matches the observed trend in the bending angle (Table 3).

To strengthen the above-mentioned correlations, Figure 15 shows a comparison between AA6063 (good bendability) and AA6013 (poor bendability) in terms of microstructure. For this observation, micrographs were taken from bending samples (Figure 15a). Figure 15b,c show the microstructure near the fracture surface of the bending samples. It was found that AA6063 exhibits a more homogenous microstructure in comparison to 6013. Alloy AA6013 shows large particles of high density, mainly Al-Fe-Si-Mn-Cu constituents. Cracks appeared due to void formation in regions of maximum strain. To illustrate fracture surfaces (Figure 15d,e), the samples were bent until complete fracture occurred. AA6063 showed a ductile, homogenous forced fracture. In contrast, AA6013 was again more inhomogeneous (shear fracture areas were observed). To investigate the microstructure of both alloys in more detail, also the undeformed material was analyzed (Figure 15f,g). AA6063 showed less constituents and more plate-like Al-Fe-Si particles (6063 has nearly no Mn, which would be required to promote the formation of globular $\alpha$-AlFeSi). In comparison AA6013 exhibited more globular particles (due to the high Mn-content), but showed an inhomogeneous and denser distribution of large constituents.

The design requirements of automotive parts often demand the presence of holes on the surface. Because hole-expansion tests measure the elongation of the material near the holes, calculating the hole-expansion ratio is of great interest in generating information about the material's susceptibility to edge cracking or edge stretching. The stress field in the formed edge where the cracks appear is similar to the stress field in the sheared edge during flanging operations. The edge condition before flanging, sheet-deformation during hole preparation, punch shape and microstructure (volume fraction and morphology of different phases) can affect the ability of the hole flange to stretch [33]. The alloy AA6013 shows the lowest hole expansion ratio, around 41\% (Table 4), which was predicted due to the high strength level of this alloy in temper T4* (Figure 5). AA6013 also contains high amounts of alloying elements, which form different intermetallic phases (e.g., Al-Fe-Si-Mn, Mg-Si, Al-Cu-Mg-Si) with a high volume fraction through the thermo-mechanical processing. These phases can cause grain boundary precipitations (mainly $\mathrm{Cu}$-rich precipitates). Fracture during deformation can then be initiated in the grain boundary through void initiation [34]. 
Figure 15. Microstructure observations on bending test samples of AA6063 and AA6013 in T4*. (a) Bending samples of AA6063 and AA6013 in temper T4*; (b) optical micrograph in the L-direction of AA6063 in T4* near the fracture surface, 500×; (c) optical micrograph in the L-direction of AA6013 in T4* near the fracture surface, 500×; (d) SEM micrograph of the fracture surface of AA6063 in T4*, red arrows $=\mathrm{Al}-\mathrm{Fe}-\mathrm{Si}$, 4,000×; (e) SEM micrograph of the fracture surface of AA6013 in T4*, red arrows $=$ Al-Fe-Si-Mn-Cu 4000×; (f) SEM micrograph of the undeformed microstructure of AA6063 in $\mathrm{T}^{*}, 1,000 \times$, white $=\mathrm{Al}-\mathrm{Fe}-\mathrm{Si}$ particles dark $=\mathrm{Al}-\mathrm{Si}-\mathrm{Mg}$ particles; (g) SEM micrograph of the undeformed microstructure of AA6013 in T4*, 1,000×, white $=$ Al-Fe-Si-Mn-Cu particles black $=$ Al-Mg-Si-Cu particles.

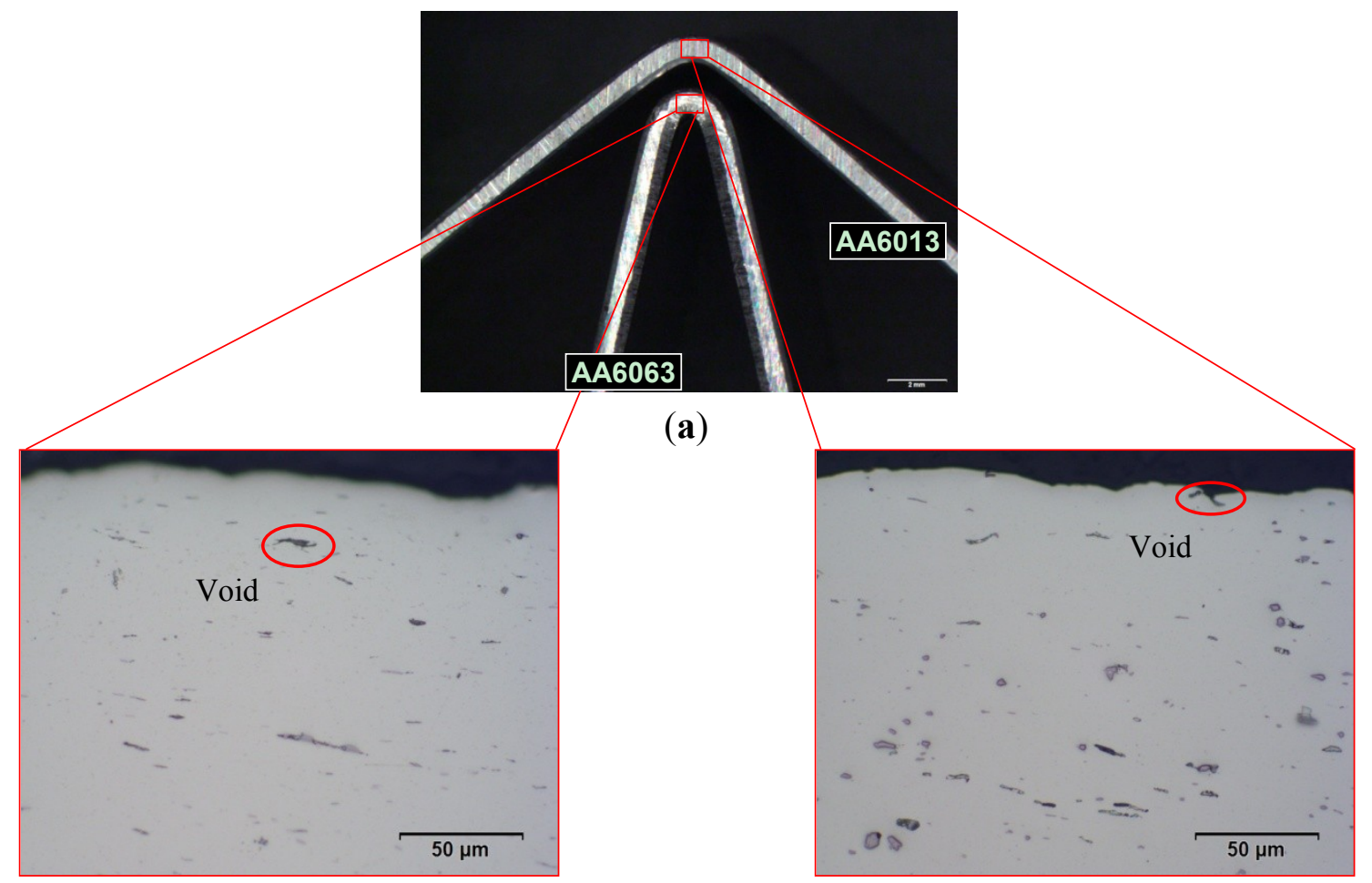

(b)

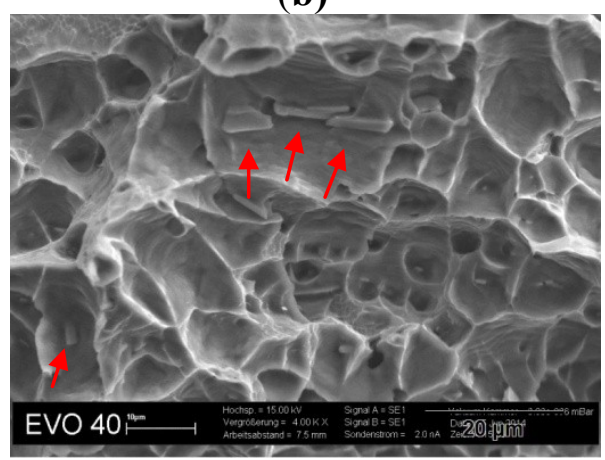

(d)

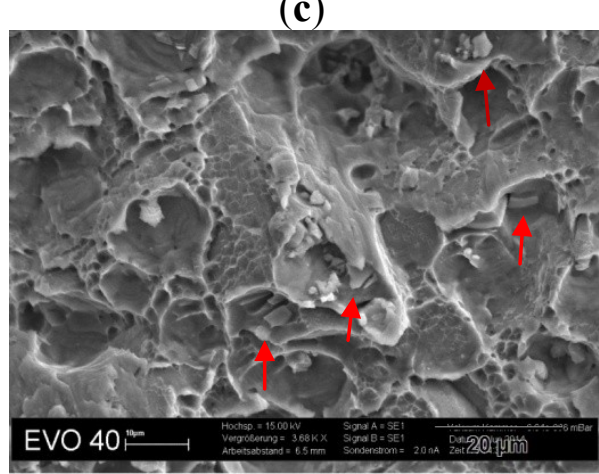

(e) 
Figure 15. Cont.

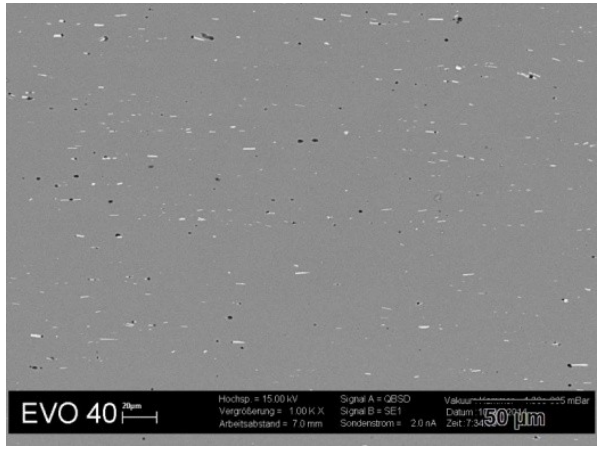

(f)

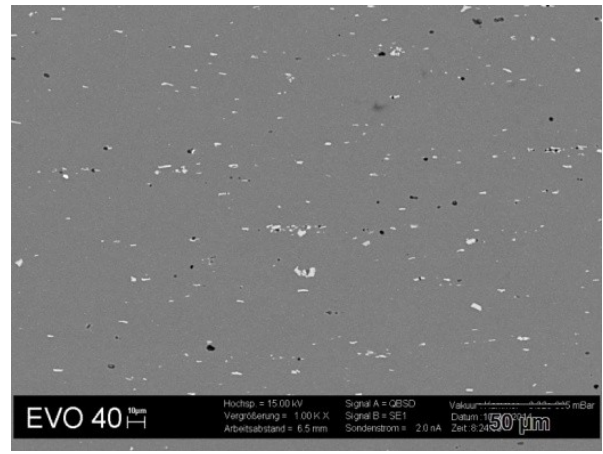

(g)

The forming test in a cross-die has been used extensively in the automotive industry to assess the formability of sheet material. The geometry of the cross-die displays typical stress states, which predominate during the manufacture of real automotive parts. Qualitatively the results of this test, summarized in Table 5, compare well with the results of the hole-expansion test (Table 4).

Overall, the forming results were found to depend on the chemical composition of the alloy and the specific testing procedure used. For example AA6013, which is widely used in the aerospace industry, showed poor forming performance during bending and hole-expansion, probably because of its very high strength level in temper T4*. However, despite its high strength, AA6013 was almost competitive in the other forming tests.

\subsection{Surface Quality}

An important consideration for sheets, which are used in outer car body panels, is their surface appearance after the final forming process. The 6xxx series alloys are known to show roping (also called ridging) after stretch forming. This phenomenon occurs on the surface of aluminum sheets during forming operations in the transverse direction (LT). The ridges formed are up to $30 \mu \mathrm{m}$ in depth and several centimeters in length, and they are arranged in a longitudinal direction (rolling direction, L). Roping is still visible after the surface of the formed sheets is painted. Such optical defects cannot be tolerated in outer skin applications. Physically, roping is caused by bands of similar crystallographic grains oriented in a preferred direction. Various studies state the predominant factors in roping to be the initial texture and the spatial distribution of grain orientations [35-39]. Roping behavior can be enhanced with a special heat treatment during the rolling process. Such treatment randomizes the distribution of grain orientations and, therefore, reduces the roping phenomena [40-42]. In this study, the investigated alloys were analyzed in terms of roping (Section 3.2.5). The applied roping test is currently used by German car manufacturers to classify outer body sheets. It was found that alloys AA6016, AA6005A and AA6063 fulfill the requirements of the outer skin material (Table 6). Only alloy AA6013 shows insufficient roping behavior for body panels.

\subsection{Corrosion Behavior}

Nearly every car manufacturer has its own extensive long-term corrosion test procedure for analyzing the corrosion behavior of aluminum sheet alloys. In this study, intergranular corrosion (IGC) 
tests were performed according to ISO 11846 method B [14]. This testing method makes possible the relatively quick classification of different Al-Mg-Si alloys. Here, several car manufacturers require a maximum IGC-depth of $300 \mu \mathrm{m}$ for body panels. Intergranular corrosion of 6xxx series alloys has been attributed to the depletion of $\mathrm{Si}$ and/or $\mathrm{Cu}$ along grain boundaries [43]. Susceptibility to IGC is, in general, strongly dependent on the thermal history during fabrication. For Al-Mg-Si alloys containing $\mathrm{Cu}$, it has been shown that the formation of a nano-scaled $\mathrm{Cu}$-enriched layer along the grain boundaries due to ageing contributes to IGC. It has been assumed that the layer serves as a precursor of the Q phase [44]. With increasing ageing temperature and time, the layer transforms into Q precipitates, and the IGC susceptibility decreases. Precipitated Si on grain boundaries is also claimed to act as a local cathodic site in alloys containing excess Si [43]. In this study (Table 7 and Figure 14), it was found that AA6013 is highly susceptible to IGC after the simulated paint bake process. This was no surprise, because of its relatively high $\mathrm{Cu}$ content and the fact that paint bake treatment is relatively brief. Therefore, the above-mentioned $\mathrm{Cu}$-layer at the grain boundaries is assumed to remain present in $\mathrm{T}^{*}$. temper. The good corrosion resistance of AA6063 and AA6005A in comparison to AA6016 can be related to their low $\mathrm{Si} / \mathrm{Mg}$ ratio, which goes hand in hand with a low amount of $\mathrm{Si}$ in excess. However, the results of corrosion tests on AA6016 would be sufficient for its use in outer car body panels, because the automotive manufacturers require a maximum IGC-depth of $300 \mu \mathrm{m}$, and AA6016 exhibits a maximum IGC-depth of $180 \mu \mathrm{m}$.

\section{Conclusions}

An investigation into typical automotive Al-Mg-Si sheet alloys with regard to the property criteria crucial in the automotive industry has inspired the following proposals regarding their use:

- Alloys AA6016 and AA6005A showed a well-weighted property profile for use in outer body panels. They exhibited excellent bendability, moderate strength in temper T**, high strength in service $\left(\mathrm{T} 6^{*}\right)$, good corrosion resistance and the best surface quality with regard to roping;

- Alloy AA6063 is very suitable for decorative inner parts, which require excellent formability during extensive deep drawing. Slight, well-defined changes in its chemical composition and/or processing route might increase the in-service strength level of this alloy, which would also make it suitable for outer body panels;

- The high-strength alloy AA6013 would be an excellent candidate for structural parts, which only require moderate formability. Unfortunately, the alloy showed a susceptibility to IGC due to its high $\mathrm{Cu}$-content; this might be minimized by special heat treatment (e.g., $205^{\circ} \mathrm{C} / 30 \mathrm{~min}$ );

- The influence of room temperature storage after sheet production on most properties is of marginal concern. AA6016, in particular, performs well in terms of long-term storage stability.

We have provided these criteria for the use of AA6016, AA6005A, AA6063 and AA6013 in the automotive industry by considering holistic aspects, such as mechanical properties, forming and corrosion behavior and achievable surface quality in service. 


\section{Author Contributions}

Ramona Prillhofer, Stefan Pogatscher, Helmut Antrekowitsch and Peter J. Uggowitzer conceived the study. Ramona Prillhofer and Gunther Rank performed the experimental tests. Helmut Antrekowitsch, Stefan Pogatscher, Josef Berneder and Peter J. Uggowitzer supervised the work. All authors contributed extensively to the data analysis and discussion. Ramona Prillhofer, Gunther Rank, Stefan Pogatscher and Peter J. Uggowitzer wrote the paper.

\section{Conflicts of Interest}

The authors declare no conflict of interest.

\section{References}

1. Elend, L.E.; Haverkamp, C. Materials in Car Body Lightweight Design. In Proceedings of the Materialien im Karosseriebau Automotive Circle International, Bad Nauheim, Germany, 11-12 May 2011.

2. Hirsch, J. Aluminium alloys for automotive application. Mater. Sci. Forum. 1997, 242, 33-50.

3. Hirsch, J. Automotive trends in aluminium-The European persepective. Mater. Forum. 2004, $28,15-23$.

4. Hecht, J.; Hoffmann, A. Audi Ultra Strategy_Lightweight Design Technologies in Competition. In Proceedings of the Materialien im Karosseriebau Automotive Circle International, Bad Nauheim, Germany, 7-8 May 2013.

5. Trosaeter, M.; Lefebvre, W.; Marioara, C.D. The influence of composition and natural aging on clustering during preaging in Al-Mg-Si alloys. J. Appl. Phys. 2010, 108, 073527:1-073527:9.

6. Shen, C.H. Pre-treatment to improve the bake-hardening response in the naturally aged Al-Mg-Si alloy. J. Mater. Sci. Technol. 2011, 27, 205-212.

7. Kim, J.H.; Kobayashi, E.; Sato, T. Effects of $\mathrm{Cu}$ addition on behavior of nanoclusters during multi-step aging in Al-Mg-Si alloys. Mater. Trans. 2011, 52, 906-913.

8. EN ISO 6892-1:2009. Metallische Werkstoffe - Zugversuch; Österreichisches Normungsinstitut: Wien, Austria, 2009.

9. DIN ISO 10275:2007. Metallsiche Werkstoffe - Blech und Band - Bestimmung des Verfestigungsexponenten im Zugversuch; DIN Deutsches Institut für Normung e. V.: Berlin, Germany, 2009.

10. DIN ISO 10113:2006. Metallische Werkstoffe - Blech und Band - Bestimmung der Senkrechten Anisotropie; DIN Deutsches Institut für Normung e. V.: Berlin, Germany, 2009.

11. EN ISO 12004-2:2008. Metallsiche Werkstoffe - Bleche und Bänder - Bestimmung der Grenzformänderungskurve; Österreichisches Normungsinstitut: Wien, Austria, 2009.

12. VDA 238-100. Plättchen-Biegeversuch für Metallische Werkstoffe; Verband der Automobilindustrie: Berlin, Germany, 2010. (in Germany)

13. ISO 16630:2009. Metallic Materials-Sheet and Strip-Hole Expanding Test; International Organization for Standardization: Geneva, Switzerland, 2009. 
14. EN ISO 11846:1995. Korrosion von Metallen und Legierungen - Bestimmung der Beständigkeit von lösungsgeglühten Aluminiumlegierungen gegen interkristalline Korrosion; Österreichisches Normungsinstitut: Wien, Austria, 2008.

15. Banhart, J.; Chang, C.S.T.; Liang, Z.; Wanderka, N.; Lay, M.D.H.; Hill, A.J. Natural aging in Al-Mg-Si alloys-A process of unexpected complexity. Adv. Eng. Mater. 2010, 12, 559-571.

16. Pogatscher, S.; Antrekowitsch, H.; Leitner, H.; Pöschmann, D.; Zhang, Z.L.; Uggowitzer, P.J. Influence of interrupted quenching on artificial aging of Al-Mg-Si alloys. Acta Mater. 2012, 60, 4496-4505.

17. Cao, L.; Rometsch, P.A.; Couper, M.J. Effect of pre-ageing and natural ageing on the paint bake response of alloy AA6181A. Mater. Sci. Eng. A 2013, 571, 77-82.

18. Edwards, G.A.; Stiller, K.; Dunlop, G.L.; Couper, M.J. The precipitation sequence in Al-Mg-Si alloys. Acta Mater. 1998, 46, 3893-3904.

19. Castany, P.; Diologenta, F.; Rossolla, A.; Despoisb, J.-F.; Bezençonb, C.; Mortensen, A. Influence of quench rate and microstructure on bendability of AA6016 aluminium alloys. Mater. Sci. Eng. A 2013, 559, 558-565.

20. Braun, R. Investigation on microstructure and corrosion behaviour of $6 \mathrm{xxx}$ series aluminum alloys. Mater. Sci. Forum. 2006, 519-521, 735-740.

21. Laughlin, D.E.; Miao W.F. The effects of $\mathrm{Cu}$ and $\mathrm{Mn}$ Content and Processing on Precipitation Hardening Behaviour in Al-Mg-Si-Cu alloy 6022. In Proceedings of the 1998 TMS Annual Meeting, San Antonio, TX, USA, 15-19 February 1998; pp. 63-79.

22. Zandbergen, H.W.; Andersen, S.J.; Jansen, J. Structure determination of $\mathrm{Mg}_{5} \mathrm{Si}_{6}$ particles in Al by dynamic electron diffraction studies. Science 1997, 277, 1221-1225.

23. Marioara, C.D.; Andersenc, S.J.; Jansena, J.; Zandbergen, H.W. The influence of temperature and storage time at RT on nucleation of the $\beta^{\prime \prime}$ phase in a $6082 \mathrm{Al-Mg-Si}$ alloy. Acta Mater. 2003, 51, 789-796.

24. Murayama, M.; Hono, K. Pre-precipitate clusters and precipitation process in Al-Mg-Si alloys. Acta Mater. 1999, 47, 1537-1548.

25. Hibino, A.; Muramatsu, T.; Saga, M.; Takata, K. Effects of microstructure on bendability of Al-Mg-Si alloys. JILM 2003, 53, 534-541.

26. Takeda, H.; Hibino, A.; Takata, K. Influence of crystal orientations on the bendability of an Al-Mg-Si Alloy. Mater. Trans. 2010, 51, 614-619.

27. Davidkov, A.; Petrov, R.H.; de Smet, P.; Schepers, B.; Kestens, L.A.I. Microstructure controlled bending response in AA6016 Al alloys. Mater. Sci. Eng. A 2011, 528, 7068-7076.

28. Mattei, L.; Danielb, D.; Guigliondab, G.; Klöckera, H.; Drive, J. Strain localization and damage mechanisms during bending of AA6016 sheet. Mater. Sci. Eng. A 2013, 559, 812-821.

29. Lassance, D.; Fabrègue, D.; Delannay, F.; Pardoen, T. Micromechanics of room and high temperature fracture in 6xxx Al alloys. Prog. Mater. Sci. 2007, 52, 62-129.

30. Mulazimoglu, M.H.; Zaluska, A.; Gruzleski, J.E.; Paray, F. Electron microscope study of Al-Fe-Si intermetallics in 6201 aluminum alloy. Metall. Mater. Trans. A 1996, 27, 929-936.

31. Kuijpers, N.C.W.; Tirelb, J.; Hanlona, D.N.; van der Zwaag, S. Quantification of the evolution of the $3 \mathrm{D}$ intermetallic structure in a $6005 \mathrm{~A}$ aluminium alloy during a homogenisation treatment. Mater. Charact. 2002, 48, 379-392. 
32. Kuijpers, N.C.W.; Vermolen, F.J.; Vuikb, C.; Koenisc, P.T.G.; Nilsenc, K.E.; van der Zwaag, S. The dependence of the $\beta$-AlFeSi to $\alpha-\mathrm{Al}(\mathrm{FeMn}) \mathrm{Si}$ transformation kinetics in Al-Mg-Si alloys on the alloying elements. Mater. Sci. Eng. A 2005, 394, 9-19.

33. Kardes, N.; Altan, T. Examining edge cracking in hole flanging of AHSS. Stamp. J. 2008, 7-8, 18-19.

34. Ramesh, R.; Bhattacharya, R.; Williams, G. Effect of ageing on the mechanical behaviour of a novel automotive grade Al-Mg-Si alloy. Mater. Sci. Eng. A 2012, 541, 128-134.

35. Beaudoin, A.J.; Bryant, J.D.; Korzekwa, D.A. Analysis of ridging in aluminum auto body sheet metal. Metall. Mater. Trans. 1998, 29A, 2323-2336.

36. Wu, P.D.; Lloyd, D.J.; Bosland, A.; Jin, H.; MacEwen, S.R. Analysis of roping in AA6111 automotive sheet. Acta Mater. 2003, 51, 1945-1957.

37. Raabe, D.; Sachtleber, M.; Weiland, H.; Scheele, G.; Zhao, Z. Grain-scale micromechanics of polycrystal surfaces during plastic straining. Acta Mater. 2003, 51, 1539-1545.

38. Wu, P.D.; Lloyd, D.J. Analysis of surface roughening in AA6111 automotive sheet. Acta Mater. 2004, 52, 1785-1798.

39. Jin, H.; Lloyd, D.J. Roping in 6111 aluminum alloys with various iron contents. Mater. Sci. Eng. A 2005, 403, 112-119.

40. Baczynski, G.J.; Guzzo, R.; Ball, M.D.; Lloyd, D.J. Development of roping in an aluminum automotive alloy AA6111. Acta Mater. 2000, 48, 3361-3376.

41. Engler, O.; Hirsch, J. Texture control by thermomechanical processing of AA6xxx Al-Mg-Si sheet alloys for automotive applications-A review. Acta Mater. 2002, A336, 249-262.

42. Bennett, T.A.; Petrov, R.H.; Kestens, L.A.I. Texture-induced surface roping in an automotive aluminium sheet. Scr. Mater. 2009, 61, 733-736.

43. Larsen, M.H.; Walmsley, J.C.; Lunder, O.; Nisancioglu, K. Effect of excess silicon and small copper content on intergranular corrosion of 6000-series aluminum alloys. J. Electrochem. Soc. 2010, 157, 61-68.

44. Svenningsen, G.; Larsena, M.H.; Nordlienb, J.H.; Nisancioglu, K. Effect of thermomechanical history on intergranular corrosion of extruded $\mathrm{AlMgSi}(\mathrm{Cu})$ model alloy. Corros. Sci. 2006, 48, 3969-3987.

(C) 2014 by the authors; licensee MDPI, Basel, Switzerland. This article is an open access article distributed under the terms and conditions of the Creative Commons Attribution license (http://creativecommons.org/licenses/by/3.0/). 